\title{
Elucidation of Microcystin-LR Degrading Mechanism of Bacillus cereus
}

\author{
Idroos F.S.* and Manage P.M. \\ Department of Zoology, University of Sri Jayewardenepura, Sri Lanka \\ *sumaiyaidroos@gmail.com
}

\begin{abstract}
Microcystin-LR (MC-LR) is a cyclic peptide produced as a secondary metabolite of certain freshwater cyanobacteria species such as, Microcystis, Anabaena, and Oscillatoria. Biodegradation of MC-LR by heterotrophic bacteria have been accepted as a reliable and cost effective method to treat MC-LR contamination. To date, more than 30 different bacterial genera have been recorded as potential MCs degraders. However, limited information are available on MC-LR degradation mechanism of bacteria. Intracellular MC-LR degradation by enzymes encoded by mlr A,B,C and D genes is the only hypothesis accepted so far. Hence, the present study focused on the elucidation of MC-LR degradation mechanism of KJ954304 Bacillus cereus $12 \mathrm{GK}$ strain which was previously isolated and characterized by authors as an efficient MC-LR degrader. Overnight grown and starved B. cereus bacterial suspension $(0.5$ $\mu \mathrm{l})$ was inoculated into $100 \mathrm{ml}$ of filter sterile $(0.2 \mu \mathrm{m})$ Beira lake water containing MC-LR at a final concentration of $5 \mu \mathrm{gml}^{-1}$. Control sample was prepared without bacterial inoculation. All flasks were incubated at $28^{\circ} \mathrm{C}$ and shaken at $100 \mathrm{rpm}$ for 3 days. Following three days of incubation $0.5 \mathrm{ml}$ sub sample aliquot was removed from both experimental and control flasks and frozen at $\left(-20^{\circ} \mathrm{C}\right)$. Then $45 \mathrm{ml}$ of experimental sample was kept aside as initial experimental sample and remaining $45 \mathrm{ml}$ of sample was filtered under sterile conditions using $0.2 \mu \mathrm{m}$ filter to remove bacterial cells. Then the filtrate was placed immediately in ice to prevent denature of enzymes. Subsequently, MC-LR was spiked to both initial experimental samples and filtered samples at a final concentration of $5 \mu \mathrm{gml}-1$, and incubated at $28^{0} \mathrm{C}, 100 \mathrm{rpm}$ for 3 days. $1 \mathrm{ml}$ aliquots were removed from initial experimental sample and filtrate sample for 0-3 days of incubation. These samples were frozen and processed for High Performance Liquid Chromatography (HPLC) analysis. A PCR analysis was carried out to detect the presence of MC-LR degrading mlr A,B,C and D genes in B. cereus. Amplifications were performed in 50 $\mu \mathrm{L}$ volumes, containing $1 \mathrm{mM}$ of each primer. A GeneAmps 2400 PCR System was utilized for the amplifications.

At the end of 3 days of experiment MC-LR concentration of the initial experimental sample with bacteria was $1.8 \mu \mathrm{gml}^{-1}$ whereas the filtrate sample without bacteria had $4.8 \mu \mathrm{gml}^{-1}$ of MC-LR. Furthermore, the PCR study confirmed the presence of mlr A,B,C and D genes in $B$. cereus. Thus, MC-LR degradation is performed as an intracellular degradation by B. cereus with the involvement of intracellular enzymes.
\end{abstract}

Keywords: Microcystin-LR, Biodegradation, Bacillus cereus, Intracellular degradation, mlr genes

Proceedings of the International Forestry and Environment Symposium 2016, Department of Forestry and Environmental Science, University of Sri Jayewardenepura, Sri Lanka. 